\title{
Coronary Risk Factors and its Reduction by Plant-Based Diet with Emphasis on Diabetes: A Preliminary Report
}

\author{
Gunadhar Panigrahi, MD, FACC, FACP, DipABLM* \\ Cardiovascular Wellness Clinic, Sentara Cardiology Specialists, USA

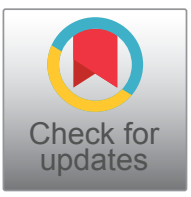

*Corresponding author: Gunadhar Panigrahi, MD, FACC, FACP, DipABLM, Cardiovascular Wellness Clinic, Sentara Cardiology Specialists, 2075 Glenn Mitchell Drive, Suite 400, Virginia Beach, VA 23456, USA, Tel: 757-507-8900, Fax: 757-301-7182

\begin{abstract}
Background: The common coronary risk factors are hypertension, hyperlipidemia, obesity and diabetes. These can be improved with Plant-Based diet.

Objective: To reduce coronary risk factors by Plant-Based diet with emphasis on diabetes.

Methods: In the first part (Part A), the subjects are 805 patients treated for hypertension, hyperlipidemia, obesity, diabetes, and coronary artery disease (CAD) from January 2012 through October 2015. Primary prevention group (without CAD) consisting of 423 patients are compared to the Secondary prevention group (with CAD) consisting of 382 patients (Table 1). The second part (Part $B$ ) is to determine the effect of plant-based diet in reducing coronary risk factors in 20 patients with diabetes, divided in to two groups, dietary compliant vs. dietary non-compliant group.
\end{abstract}

Results: Part A: Analysis of risk factors for CAD shows that risk ratio for hypertension is $1.4803(p=0.0002)$, hyperlipidemia $1.9118(p=0.0023)$, diabetes $1.5357(p<0.0001)$, obesity $0.8637(p=0.0565)$, age $\geq 65$ years $1.4665(p<$ 0.0001 ), male sex 1.6509 ( $p<0.0001$ ) (Table 2). Gender related analysis of $C A D$ risk factors indicated higher incidence of diabetes in females compared to males (Table 3 ).

Part B: In the diabetic cohort analysis of risk factors between dietary compliant and non-compliant group (Table 4) showed an average drop in $\mathrm{HbA} 1 \mathrm{c}$ of $3.03 \%$ vs. decrease of $0.03 \%, p=0.0049$, total cholesterol decreased by 68.8 $\mathrm{mg} / \mathrm{dl}$ vs. increase of $13.2 \mathrm{mg} / \mathrm{dl}, \mathrm{p}=0.0018$, weight decreased by $9.02 \mathrm{~kg}$ vs. increase of $1.78 \mathrm{~kg}, \mathrm{p}=0.0071$, BMI decreased by $3.28 \mathrm{~kg} / \mathrm{m}^{2}$ vs. increase by $1.22 \mathrm{~kg} / \mathrm{m}^{2}, \mathrm{p}=$ 0.0071 . There was no significant difference for systolic and diastolic blood pressures between the two groups (Table 5). The reduction in $\mathrm{HbA1c}$ was associated with reduction in the number of antidiabetic medications only in the compliant group and this is unchanged in the non-compliant groups, a decrease from 2.1 to 1.2 vs. no change from 2.6 to $2.6, p=$ 0.0753 (Table 6).
Conclusion: Plant-based diet improved coronary risk factors, including decrease in $\mathrm{HbA} 1 \mathrm{c}$ in the patients with diabetes. This is associated with the need for reduced number of antidiabetic medications.

\section{Keywords}

Plant-Based Diet; Reversing Diabetes

\section{Abbreviations and Acronyms}

CAD: Coronary Artery Disease; BMI: Body Mass Index; HbA1c: Glycosylated Hemoglobin; TMAO: Trimethylamine-N-oxide; VEG: Vascular Endothelial Glycocalyx

\section{Introduction}

Heart disease has been the leading cause of death since 1933 in the US according to the mortality records from CDC [1,2]. In 2009 coronary heart disease accounted for $64 \%$ of the cardiac deaths. This is due to diet high in processed foods, high in meat, saturated fat, added sugars and other high glycemic index carbohydrate, along with sedentary lifestyle $[1,3]$. A comprehensive survey of cardiovascular disease of the New Guinea highlanders indicated rare incidence of ischemic heart disease, and no diabetes or gout. Their diet consisted of more than 90 per cent of the calories coming from carbohydrate, and the consumption of protein and salt were about 25 and 1 gram daily [4]. Campbell, et al. in the Cornell China study found that in rural China, fat intake was less than half, fiber intake was 3 times higher and animal protein intake was about $10 \%$ that of US. In rural China, mean serum cholesterol level was $127 \mathrm{mg} /$ dl vs. $203 \mathrm{mg} / \mathrm{dl}$ in the United States. Coronary artery disease mortality was 16.7-fold greater for US men and 5.6-fold greater for US women than for the Chinese [5]. 
Table 1: Patients data $(n=805)$ - (1) Primary Prevention Group (without CAD) and, (2) Secondary Prevention Group (with CAD).

\begin{tabular}{|l|l|l|l|l|l|l|}
\hline Groups under Study & $\begin{array}{l}\text { Average Age (yrs.) } \\
\text { (Range) }\end{array}$ & $\begin{array}{l}\text { Average } \\
\text { BMI(kg/m²)(Range) }\end{array}$ & CAD & HTN & CHOL & DM \\
\hline Primary Prevention $(\mathrm{n}=423)$ & 64.1 & 31.9 & 0 & 321 & 388 & 108 \\
& $(18-96)$ & $(17.7-63.9)$ & $(0 \%)$ & $(75.9 \%)$ & $(91.7 \%)$ & $(25.5 \%)$ \\
\hline Secondary Prevention $(\mathrm{n}=382)$ & 69.1 & 30.3 & 382 & 329 & 370 & 172 \\
& $(33-93)$ & $(18.2-65.2)$ & $(100 \%)$ & $(86.1 \%)$ & $(96.9 \%)$ & $(45.0 \%)$ \\
\hline
\end{tabular}

BMI: Body Mass Index; CAD: Coronary Artery Disease; HTN: Hypertension; CHOL: Cholesterol; DM: Diabetes Mellitus

Table 2: Risk factors for CAD - All patients $(n=805)$.

\begin{tabular}{|l|l|l|l|l|l|}
\hline Risk Factors & $\begin{array}{l}\mathbf{N}_{\mathbf{1}} / \mathbf{T}_{\mathbf{1}} \\
\text { with CAD }\end{array}$ & $\begin{array}{l}\mathbf{N}_{\mathbf{2}} / \mathbf{T}_{\mathbf{2}} \\
\text { without CAD }\end{array}$ & Risk Ratio & $\mathbf{9 5 \%} \mathbf{C l}$ & $\mathbf{p - v a l u e ~}$ \\
\hline Hypertension & $329 / 382$ & $321 / 423$ & 1.4803 & $1.747-1.8653$ & 0.0002 \\
\hline Hyperlipidemia & $370 / 382$ & $388 / 423$ & 1.9118 & $1.1669-3.1322$ & 0.0023 \\
\hline Diabetes & $172 / 382$ & $108 / 423$ & 1.5357 & $1.3351-1.7664$ & $<0.0001$ \\
\hline Obesity (BMI > = 30) & $182 / 382$ & $231 / 423$ & 0.8637 & $0.7467-0.9992$ & 0.0565 \\
\hline Elderly (> =65 years) & $266 / 382$ & $225 / 423$ & 1.4665 & $1.2424-1.7310$ & $<0.0001$ \\
\hline Male Sex & $261 / 382$ & $195 / 423$ & 1.6509 & $1.4006-1.9459$ & $<0.0001$ \\
\hline
\end{tabular}

This data shows the relative risk of having CAD from the risk factors for all patients in the study:

Hypertension to CAD, Hyperlipidemia to CAD, Diabetes to CAD, age $>=65$ years to CAD, Male Sex to CAD.

$\mathrm{N}_{1}=$ Number of Patients with CAD

$\mathrm{N}_{2}=$ Number of Patients without CAD

$\mathrm{T}_{1}=$ Total number of patients with CAD

$\mathrm{T}_{2}=$ Total number of patients without CAD

Table 3: CAD risk factors Male/Female - Secondary Prevention Group (with CAD, $n=382$ ) and Primary Prevention Group (without CAD, $n=423$ ).

\begin{tabular}{|l|l|l|l|l|l|l|}
\hline \multirow{2}{*}{ Risk Factors } & Sex & $\begin{array}{l}\text { N/T } \\
\text { Secondary } \\
\text { Prevention } \\
\text { Group }\end{array}$ & $\begin{array}{l}\text { N/T } \\
\text { Primary } \\
\text { Prevention } \\
\text { Group }\end{array}$ & Risk Ratio & 95\% Cl \\
\hline \multirow{2}{*}{ Hypertension } & Male & $219 / 261$ & $152 / 195$ & 1.0765 & $0.9822-1.1797$ & 0.1150 \\
\hline \multirow{2}{*}{ Hyperlipidemia } & Female & $110 / 121$ & $169 / 228$ & 1.2265 & $1.1151-1.3489$ & 0.0002 \\
\hline \multirow{2}{*}{ Diabetes } & Male & $254 / 261$ & $181 / 195$ & 1.0485 & $1.0034-1.0955$ & 0.0258 \\
\hline \multirow{2}{*}{ Obesity $($ BMI $>=30)$} & Female & $116 / 121$ & $207 / 228$ & 1.0559 & $0.9989-1.1162$ & 0.0915 \\
\hline & Male & $114 / 261$ & $51 / 195$ & 1.6700 & $1.2709-2.1946$ & 0.0001 \\
\hline & Female & $58 / 121$ & $57 / 228$ & 2.0826 & $1.5702-2.7624$ & $<0.0001$ \\
\hline Elderly $($ age $>=65)$ & Female & $131 / 261$ & $107 / 195$ & 0.9147 & $0.7675-1.0902$ & 0.3441 \\
\hline & Male & $180 / 261$ & $100 / 195$ & 1.3448 & $1.1469-1.5769$ & 0.0001 \\
\hline & Female & $86 / 121$ & $125 / 228$ & 1.2964 & $1.1006-1.5270$ & 0.0039 \\
\hline
\end{tabular}

$\mathrm{N}$ : Number of male or female with risk factors in respective groups.

$\mathrm{T}$ : Total number of male or female in respective groups.

The Framingham Heart Study illustrated the contribution of individual risk factors leading to CAD [6]. With diabetes posing twofold to threefold increased risk [7]. This knowledge allowed clinicians to predict possible rewards in the form of improved risk profiles for patients who can make the appropriate changes in smoking, eating, and exercise habits [8]. The Multiple Risk Factor Intervention Trial (MRFIT) administered during 1970s decreased CAD mortality with intervention against risk factors [9]. In the US, there is steady decline in the incidence of deaths from CAD from 1980 through 2011 which now has reached a plateau, with some segments of the population now showing increasing trend in mortality [2]. The decline in mortality has been attributed due to reduction in major coronary risk factors, namely high cholesterol, high blood pressure, reduction in smoking, 
and increased physical activity; and the other half from improved management of acute myocardial infarction, percutaneous transluminal coronary angioplasty/stent (PTCA/STENT), and coronary artery bypass graft (CABG) surgery; and secondary prevention after myocardial infarction [10].

The rate of decline in heart disease mortality decelerated substantially after 2011. Reported as percentage $(95 \% \mathrm{Cl})$, the annual rate of decline for $2000-2011$ is $3.69 \%$ (3.51 to $3.87 \%$ ) and the rates for $2011-2014$ is $0.76 \%(-0.06$ to $1.58 \%)$. This deceleration in mortality is attributed due to the rising prevalence of obesity and diabetes [11].

The American Heart Association (AHA) has set forth a goal "to improve the cardiovascular health of all Americans by $20 \%$ while reducing deaths from CVD by $20 \% "$ by 2020 . The AHA has outlined 7 metrics to improve cardiovascular health - by achieving i) Cessation of smoking, ii) BMI $<25 \mathrm{~kg} / \mathrm{m}^{2}$, iii) $\geq 150 \mathrm{~min} /$ week moderate intensity exercise or $\geq 75 \mathrm{~min} /$ week vigorous intensity exercise or combination, iv) Favorable healthy diet, v) Total cholesterol $<200 \mathrm{mg} / \mathrm{dl}$ without treatment, vi) Blood pressure $<120 / 80 \mathrm{~mm}$ of $\mathrm{Hg}$ without treatment, and vii) Fasting glucose $<100 \mathrm{mg} / \mathrm{dl}$ without treatment [12].

To-date cardiovascular care has been predominantly focused on disease management with control of individual risk factors, mostly by pharmacologic treatment. Lifestyle medicine with its comprehensive approach and whole-food plant-based (WFPB) diet will have significant impact in reducing these risk factors.

Stampfer, et al. followed 84,129 women participating in the Nurses' Health Study who were free of diagnosed cardiovascular disease, cancer, and diabetes at baseline in 1980 . During the 14 years of follow up, they documented 1128 major coronary events (296 deaths from coronary heart disease and 832 nonfatal myocardial infarctions). The experience from this study indicated, women in the low-risk category were those who have not been currently smoking, had a body-mass index under 25 , consumed an average of at least half a drink of alcoholic beverage per day, engaged in moderate-to-vigorous physical activity, and scored in the highest 40 percent of the cohort for consumption of a diet high in cereal fiber, marine $n-3$ fatty acids, and folate with a high ratio of polyunsaturated to saturated fat, and low in trans-fat and food low in glycemic load. Women in the low-risk category ( 3 percent of the population) have a relative risk of coronary events of $0.17(95 \% \mathrm{Cl}, 0.07$ to 0.41 ) as compared to the other women. Eighty-two percent of coronary events in the study cohort $(95 \% \mathrm{Cl}$, 58 to $93 \%$ ) were attributed due to lack of adherence to low-risk lifestyle pattern [13].

Morrison had demonstrated the effectiveness of low-cholesterol and low-fat diet in reducing mortality in a group of patients with known coronary artery disea- se [14]. Blankenhorn, et al. had shown that regression of atherosclerosis is possible with diet and cholesterol lowering medications [15]. Dean Ornish was the first to show that lifestyle changes were enough to reverse coronary atherosclerosis [16]. Esselstyn, et al. have demonstrated the success of plant-based nutrition in arresting and reversing cardiovascular disease [17]. A higher quality diet was associated with lower risk of recurrent cardiovascular events among people 55 years or above was observed with cardiovascular disease (CVD) or diabetes mellitus [18]. A remarkable decline in cardiovascular risk factors and mortality has been observed in Finland since 1972, after introduction of diet and lifestyle changes [19].

Lifetime risk estimates for total cardiovascular disease were high, $>30 \%$ for all individuals, even those with optimal risk factors in middle age. However, maintenance of optimal risk factor levels in middle age was associated with substantially longer morbidity-free interval $[20,21]$.

Fang, et al. in a study of 356,441 U.S. adults in a telephone survey showed that only $3.3 \%$ of the population was in ideal cardiovascular health, and $9.9 \%$ in poor cardiovascular health [22]. Folsom, et al. published data from the ARIC (Atherosclerosis Risk in Communities) study, a prospective cohort study from 4 U.S. communities. This study enrolled 15,792 men and women 45 to 64 years of age free of cardiovascular disease. After median follow-up of 18.7 years with 3,063 overall CVD events, almost one-half of the participants with no ideal health factors experienced CVD events in contrast to no events those have all 7 ideal health factors at baseline [23]. The NHANES (National Health and Nutritional Examination) study found similar associations between ideal cardiovascular health and outcomes, in a nationally representative of 44,959 adults [24]. Chomistek, et al. in The Nurses' Health Study II (NHSII) in 88,940 women followed for 20 years, found that women who engaged in all 6 healthy lifestyle choices had 92\% lower risk of CAD, and a $66 \%$ lower risk for clinical CVD risk factors [25].

In a prospective cohort of healthy men on low-risk diet together with moderate consumption of alcohol with low-risk lifestyle behaviors, including not smoking, being physically active and avoiding abdominal obesity had an impressive $86 \%$ lower risk of myocardial infarction, as reported by Akesson, et al. in Swedish men. But these combinations of healthy behaviors were present in only $1 \%$ of the men [26].

Strong, et al. in their autopsy study documented that the process of atherosclerosis begins in youth. Fatty streaks and clinically significant raised lesions increase rapidly in prevalence and extent during the 15 to 34 years of age [27]. Tuzcu, et al. by intravascular ultrasound, demonstrated that coronary atherosclerosis begins at young age and that lesions are present in 1 of 6 teenagers [28]. Atherosclerosis is a progressive disease, whi- 
ch continues to progress over decades, leading to both fatal and nonfatal cardiovascular events, including myocardial infarction, stroke, and sudden death.

It is recognized that with primordial and primary prevention, cardiovascular disease could be largely preventable $[29,30]$. Both genetic and lifestyle factors contribute to individual-level risk of coronary artery disease. Khera, et al. have studied the outcome of 55,685 participants and have found that amongst the high genetic risk pool, a favorable lifestyle was associated with a nearly $50 \%$ lower risk of coronary artery disease than was an unfavorable lifestyle [31].

\section{Methods}

The present study is a prospective observational study generated from an outpatient cardiology wellness clinic and consists of two parts: Part $A$, is to determine the degree of risk factors contributing to CAD. The subjects in this study were 805 consecutive patients seen in the clinic by a single provider (the author) from January 2012 through October 2015. They had hypertension, hyperlipidemia, diabetes, CAD and/or combination of these conditions. The group without CAD (primary intervention) consisted of 423 patients compared with the group with CAD (secondary prevention) consisted of 382 patients (Table 1 ).

Part $B$ is to determine the effect of Plant-Based diet on reversing type 2 diabetes, a major risk factor for CAD. There are 20 subjects in this study group, and their participation was voluntary. They all have received standard diabetes medical treatment from their primary care providers and/or endocrinologists. The wellness clinic consultation only provided education and counseling on Plant-Based diet to improve coronary risk factors including reversing diabetes when present. In the first encounter in the wellness clinic, which is an hour of consultation, they all received intensive education on the principles of reversing type 2 diabetes with a Plant-Based diet. This consisted of vegetables, beans, whole grains, fruits, and some nuts and seeds (Figure 1 ). On this diet, $65 \%$ calories are coming from complex carbohydrates, $20 \%$ from protein, and $15 \%$ from fat. They were also educated on the health benefit of a high-fiber diet leading to weight reduction, improvement in blood sugar, and overall cardiovascular health [32]. In addition, they were counseled to maintain ideal body weight and to participate in regular exercise for at least 150 minutes per week. They all received brochures, written material on meal plans, foods to avoid particularly animal-derived products which are rich in saturated fat and cholesterol, and to avoid highly processed foods. During the follow up visits clinical progresses were discussed, with additional counseling on the areas where they have not made satisfactory progress according to the 7 metrics of AHA [12].

On the final analysis, those who have complied with the prescribed diet are a group of 10 subjects (compliant group) and have achieved $\mathrm{HbA} 1 \mathrm{c}$ of $<7.0 \%$, are compared with the 10 subjects who have not able to make the necessary dietary changes (non-compliant group) and have not achieved $\mathrm{HgbA} 1 \mathrm{c}<7.0 \%$.

\section{Results}

Part A: For CAD risk ratio for Hypertension was1.4803 $(p=0.0002)$, hyperlipidemia $1.9118(p=0.0023)$, diabetes 1.5357 ( $p<0.0001)$, age $\geq 651.4665$ ( $p<0.0001)$, male gender 1.6509 ( $p<0.0001)$ and obesity 0.8724 ( $p$ $=0.0565$ ). It was very remarkable to see the incidence of diabetes in patients with CAD was almost twice (45\%) compared to the patients without CAD (25.5\%) (Table 1, Table 2 and Table 3).

Part B: In this cohort of patients with diabetes, the dietary compliant group was compared to the non-compliant group (Table 4), who had achieved significant reduction in $\mathrm{HbA} 1 \mathrm{c}$ (decrease of $3.03 \%$ vs. decrease of $0.03 \%$, ( $p=0.0049$ ), total cholesterol (decrease of 68.8 $\mathrm{mg} / \mathrm{dl}$ vs. increase of $13.2 \mathrm{mg} / \mathrm{dl}, \mathrm{p}=0.0018$ ), weight (decrease of $9.02 \mathrm{~kg}$ vs. increase of $1.78 \mathrm{~kg}, \mathrm{p}=0.0071$ ), BMI (decrease of $3.28 \mathrm{~kg} / \mathrm{m}^{2}$ vs. increase of $1.22 \mathrm{~kg} /$ $\left.\mathrm{m}^{2}, \mathrm{p}=0.0096\right)$. There was measurable improvement in blood pressure although statistical significance was not reached (Table 5, Figure 2 and Figure 3). In addition, there was a reduction in the number of antidiabetic medications by 0.9 on an average in the dietary compliant group compared to no change in the dietary non-compliant group ( $p=0.0753$ ) (Table 6 and Figure 4).

\section{Statistical analysis}

For statistical analysis, Fisher's exact probability test has been used for the Part A, i.e., the Primary and Secondary coronary risk factors section of study; and for the Part $B$, the diabetic cohort study group, t-test for independent variables has been used.

\section{Discussion}

The coronary risk factors analysis (Part A) study showed adverse correlation between CAD with hypertension, hyperlipidemia, diabetes, older age, and male gender. The Western Diet [3], which is high in processed food, saturated fat, animal-derived products [33], refined grains, high in calorie- density, and nutritionally depleted, is the harbinger of most of the chronic diseases including atherosclerosis and diabetes [3,34]. In addition, foods containing meat, cheese and eggs, rich in phosphatidyl-choline and choline when are metabolized by intestinal microbiota form trimethylamine and its conversion to trimethylamine- $\mathrm{N}$-oxide (TMAO). This compound is toxic to the endothelium of blood vessels causing atherosclerosis and is associated with major adverse cardiovascular events [35].

These dietary habits and its relation to atherosclerosis have been experimentally elucidated in the laboratory [36]. The cause of insulin resistance leading to type 


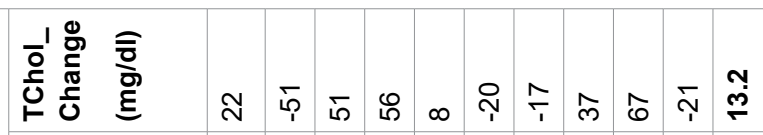

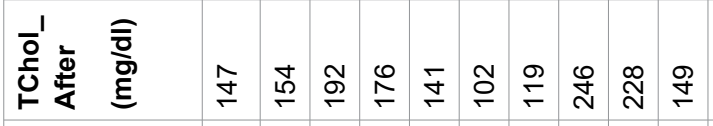

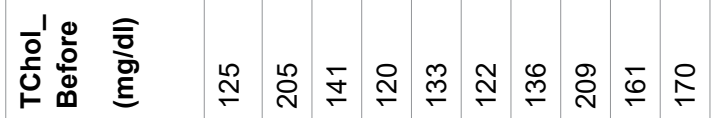

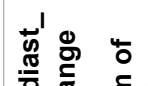

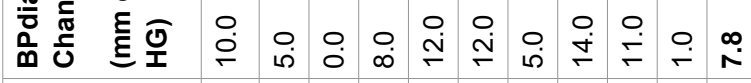

苋

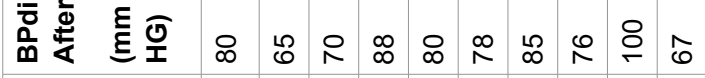

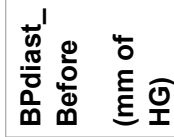

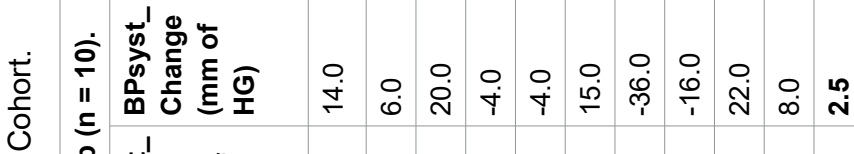

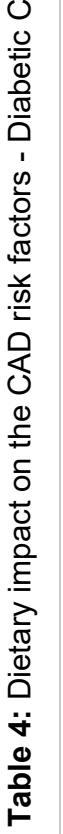

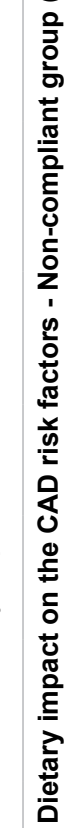

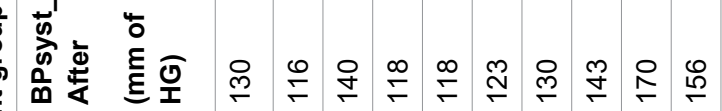

要哭

㐫造

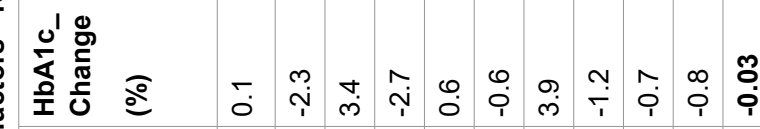

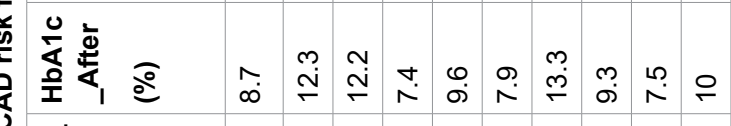
品

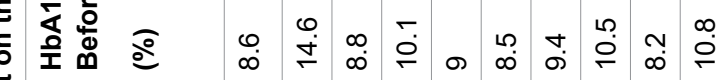
离

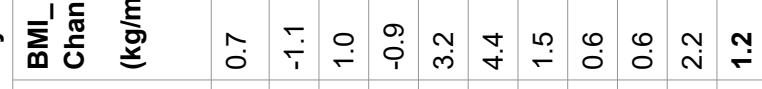

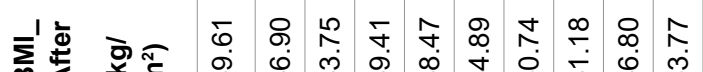

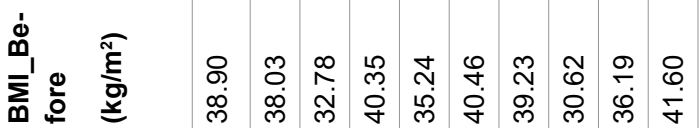

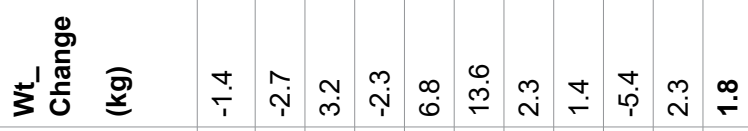

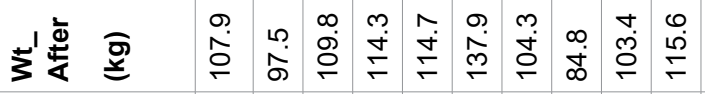

䒓䒾

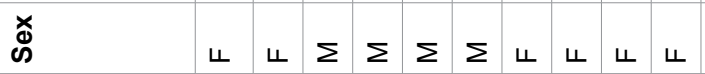

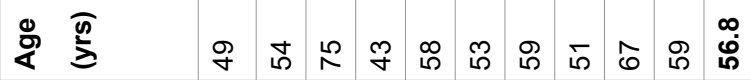

衣

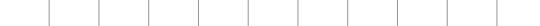

을

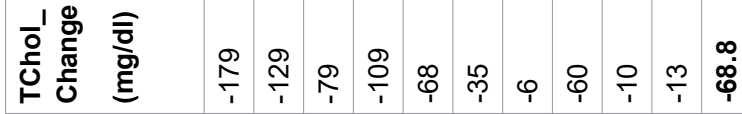

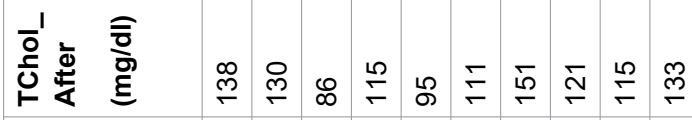

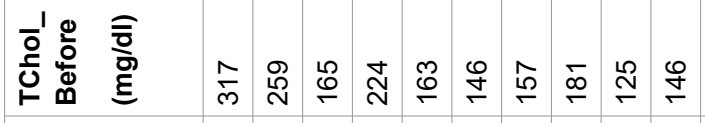
营 吕

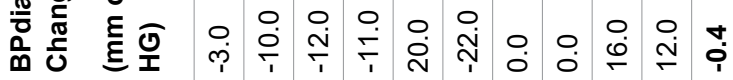
空

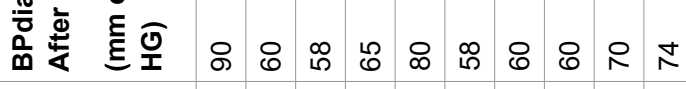
密。广

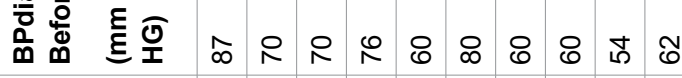

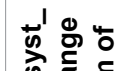

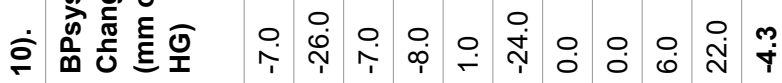
"

产商㐫离

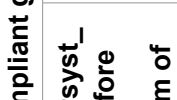

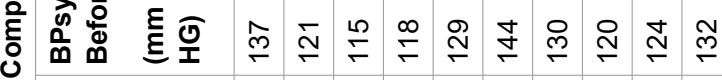

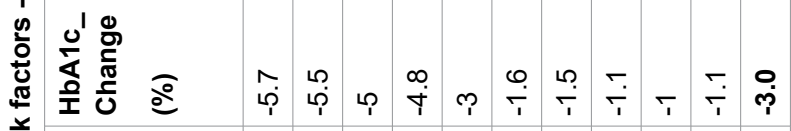

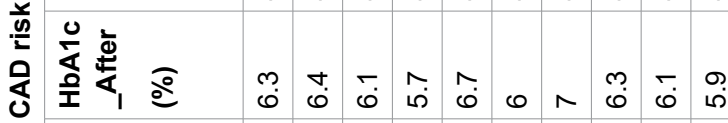

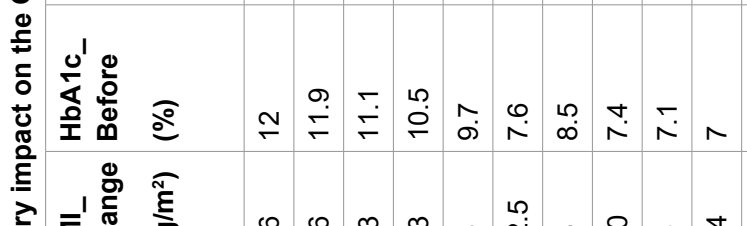

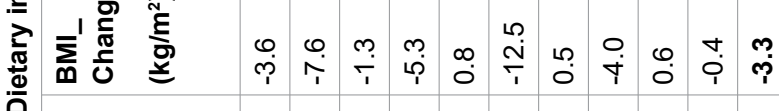

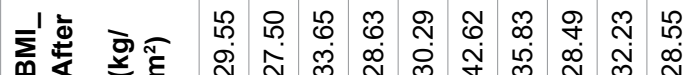

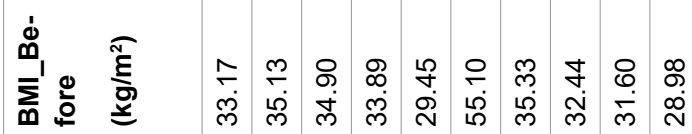

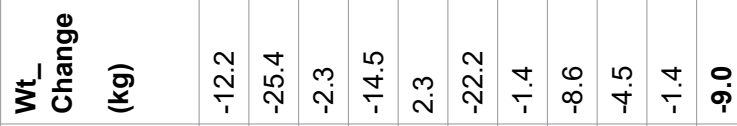

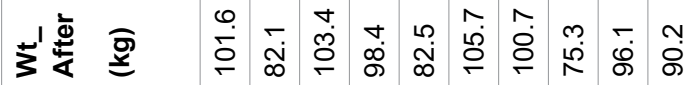

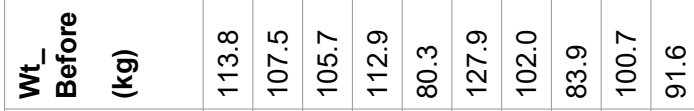
œ $\quad \Sigma \Sigma \Sigma \Sigma \Sigma L \Sigma L \Sigma \Sigma$

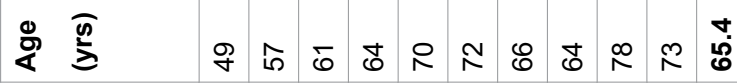

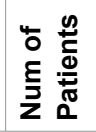


2 diabetes is found to be due to ectopic fat deposition in the liver, pancreas, and muscle, and its potential reversibility has been characterized [37-40]. With appropriate dietary interventions most cases of type 2 diabetes can even be reversed [40-46].

Diabetes carries twofold to threefold risk for clinical manifestation of CAD [7]. Similar to what is observed in the present study. In addition, the present study also indicated diabetes is associated with a higher cardiovascular risk in females than males, 2.0826 (95\% $\mathrm{Cl}, 1.5702-2.7624, \mathrm{p}=<0.0001)$ to $1.6700(95 \% \mathrm{Cl}$, 1.2709-2.1946) $p=0.0001$ respectively (Table 3 ), similar to what has been the experience of other researchers [47]. Lifestyle changes and treatment with metformin both have reduced the incidence of diabetes in persons at high risk. But lifestyle intervention was found to be more effective than metformin [48]. The American Heart Association's nutrition committee, in addition to improving diet, has incorporated lifestyle as a critical component to reduce cardiovascular disease risk in the general population [49]. Selvin, et al. in a population of nondiabetic adults found that glycated hemoglobin was associated with risk of diabetes, and more strongly associated with risks of cardiovascular disease and death [50]. In a population-based cohort study of 24,752 metformin initiators, early glycemic control and magnitude of $\mathrm{HbA} 1 \mathrm{c}$ reduction was associated with a lower risk of cardiovascular events and death in patients with type 2 diabetes [51].

In spite of significant advances in the management of heart disease, cardiovascular disease remains the leading cause of death in the US [1,2]. A plant-based diet, high in complex carbohydrates, moderate in protein, high in fiber, low in fat, free of cholesterol, rich in vitamins, minerals, antioxidants, phytosterols, and other phytochemicals hold a great promise in reducing coronary risk factors, including reducing $\mathrm{HbA1c}$ in diabetics, and in reducing most of the chronic diseases encountered in the modern society $[3,45,46,52]$. The American Diabetic Association has endorsed the health benefits of vegetarian diets in the prevention and treatment of chronic diseases in reducing cardiovascular risks including diabetes [46].

The impact of type 2 diabetes on CVD outcomes remains high [2]. The risk of macrovascular complications increases with severity of hyperglycemia, thus suggesting that the relation between metabolic disturbances and vascular damage is approximately linear. Although current antidiabetic drugs are highly effective for the management of hyperglycemia, most T2DM patients remain exposed to substantial risk for CVD. The recent additions of sodium glucose co-transporter 2 inhibitors (SGLT2) and glucose-like peptide-1 receptor agonists (GLP-1 RAs) hold some promise in reducing cardiovascular morbidity and mortality [53].

Patients with diabetes have vascular vulnerability to atherogenic insults, leading to accelerated atherogenesis. Hyperglycemia has been associated with endothelial permeability, increased leukocyte-endothelial adhesion, and impaired nitric oxide (NO) bioavailability. The glycocalyx covers the endothelium and consists of endothelial cell-derived proteoglycans, glycoproteins, and adsorbed plasma proteins. The layer has been shown to orchestrate vascular homeostasis. Hyperglycemia, by its pro-oxidant, pro-inflammatory stimulus, has been associated with profound reduction in vascular endothelial glycocalyx (VEG) volume. As a result, the release of NO in response to shear stress is dramatically reduced [54]. Oxygen derived free radicals has been found to disrupt the endothelial cell surface layers, leading to vascular wall adhesions by oxidized low density lipoprotein (OX-LDL) and increase platelet-endothelial cell adhesion, leading the early stages of atherosclerosis [55].

Nakanishi, et al. studied plaque progression by semi-automated quantitative plaque software on coronary computed tomography angiography between diabetes $(n=71)$ and non-diabetes $(n=71)$ patients. There were no significant differences between the two groups in all matched variables at entry. The baseline volumes in each plaque did not differ. But after the mean scan interval of $3.4 \pm 1.8$ years, diabetic patients showed a 2 -fold greater progression in normalized total plaque volume (TPV) than the non-diabetic patients $\left(52.8 \mathrm{~mm}^{3}\right.$ vs. $118.3 \mathrm{~mm}^{3}, \mathrm{p}=0.005$ ) [56]. Kim, et al. studied the natural history of diabetic coronary atherosclerosis by quantitative measurement of serial coronary computed tomographic angiography: results of the PARADIGM study in 1,602 patients with median scan interval of 3.8 years. This study demonstrated plaque progression was more common in diabetics than non-diabetics ( $85 \%$ vs. $76 \%, p=0.006)$. In addition, this study revealed very high rates of plaque progression occurring both in the presence or absence of diabetes, in this relatively stable patient population [57]. This calls for even more aggressive preventive measures for coronary atherosclerosis. In clinical and epidemiological studies by dietary interventions with low-fat vegetarian diet, diabetes remission and cardiovascular risk factor improvements have been achieved [58-60].

In this Part B section (diabetic cohort) of the study, in the dietary compliant group of all 10 patients, $\mathrm{HbA} 1 \mathrm{c}$ has improved significantly compared to the group who have not able to comply with the prescribed diet (Table 4, Table 5, Figure 2 and Figure 3). The dramatic drop in $\mathrm{HbA1c}$ in the compliant group is explained by their early referral to our cardiovascular wellness clinic, and their prompt adoption of a plant-based diet. This also has been the experience of other researchers [61]. Along with this favorable change, there is corresponding reduction in the number of antidiabetic medications in the compliant group while no change was observed in the non-compliant group (Table 6 and Figure 4). Although, this did not reach statistical significance betwe- 
Table 5: Dietary impact on CAD risk factors.

\begin{tabular}{|c|c|c|c|}
\hline Risk Factors & Non-Compliant $(n=10)$ & Compliant $(n=10)$ & p-Value \\
\hline $\begin{array}{l}\text { Weight }(\mathrm{kg}) \\
(95 \% \mathrm{Cl})\end{array}$ & $\begin{array}{l}1.78 \\
( \pm 3.89)\end{array}$ & $\begin{array}{l}-9.02 \\
( \pm 6.71)\end{array}$ & 0.0071 \\
\hline $\begin{array}{l}\text { BMI }\left(\mathrm{kg} / \mathrm{m}^{2}\right) \\
(95 \% \mathrm{Cl})\end{array}$ & $\begin{array}{l}1.22 \\
( \pm 1.22)\end{array}$ & $\begin{array}{l}-3.28 \\
( \pm 3.07)\end{array}$ & 0.0096 \\
\hline $\begin{array}{l}\mathrm{HbA} 1 \mathrm{c}(\%) \\
(95 \% \mathrm{Cl})\end{array}$ & $\begin{array}{l}-0.03 \\
( \pm 1.56)\end{array}$ & $\begin{array}{l}-3.03 \\
( \pm 1.43)\end{array}$ & 0.0049 \\
\hline $\begin{array}{l}\text { Systolic Blood Pressure }(\mathrm{mm} \text { of } \mathrm{Hg}) \\
(95 \% \mathrm{Cl})\end{array}$ & $\begin{array}{l}2.5 \\
( \pm 12.88)\end{array}$ & $\begin{array}{l}-4.3 \\
( \pm 9.96)\end{array}$ & 0.1164 \\
\hline $\begin{array}{l}\text { Diastolic Blood Pressure }(\mathrm{mm} \text { of } \mathrm{Hg}) \\
(95 \% \mathrm{Cl})\end{array}$ & $\begin{array}{l}7.8 \\
( \pm 3.46)\end{array}$ & $\begin{array}{l}-0.4 \\
( \pm 9.69)\end{array}$ & 0.0993 \\
\hline Total Cholesterol (mg/dL) $(95 \% \mathrm{Cl})$ & $\begin{array}{l}13.2 \\
( \pm 28.32)\end{array}$ & $\begin{array}{l}-68.8 \\
( \pm 40.72)\end{array}$ & 0.0018 \\
\hline
\end{tabular}

Cl: Confidence Interval

\section{Vegetarian Diet (\% of Calories)}

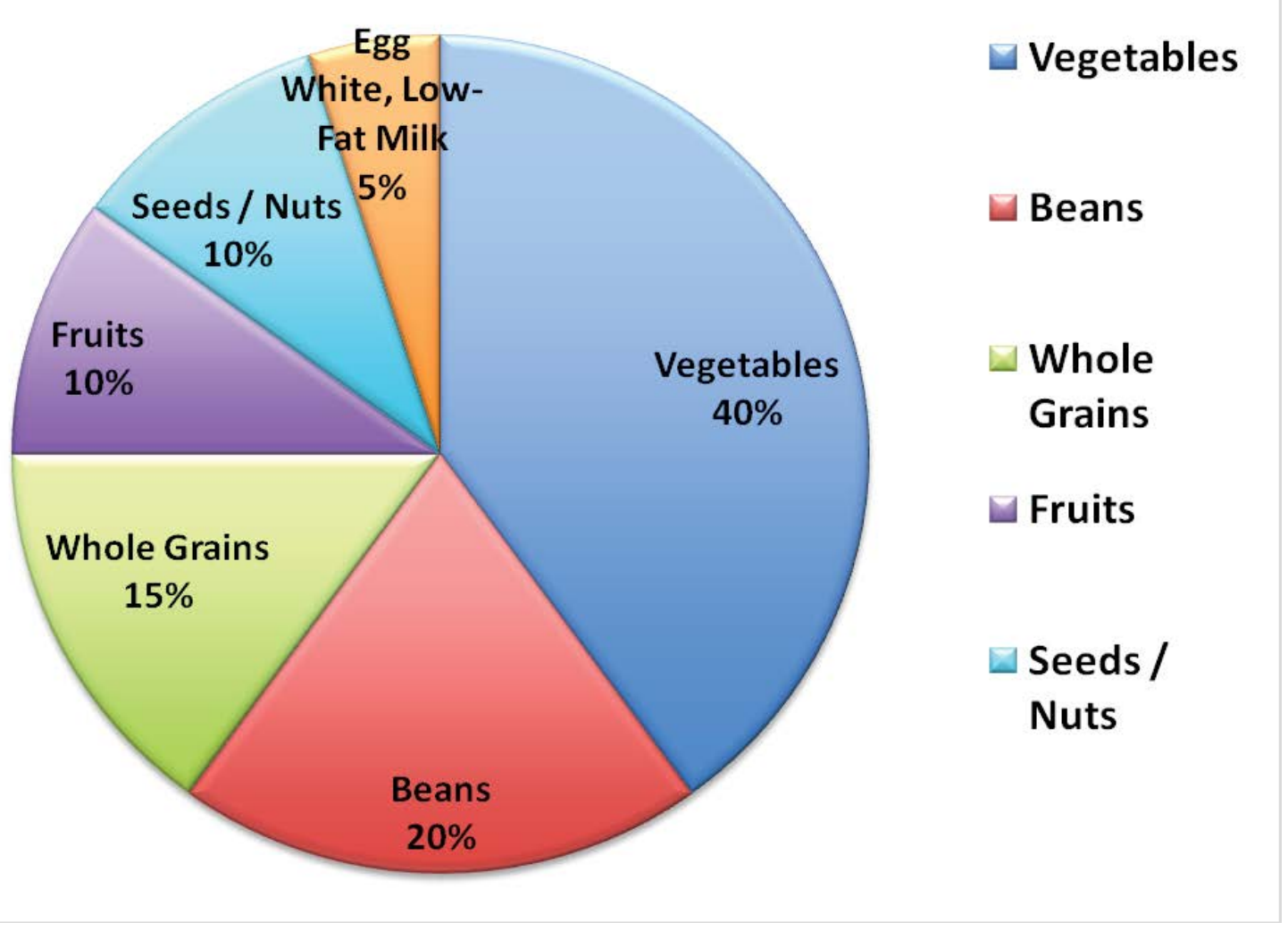

Figure 1: Composition of the interventional diet.

en the two groups, likely due to small sample size, the trend is obvious. In addition, there has been associated improvement in weight, blood pressure, and lipids.

\section{Conclusion}

This study supports that Plant-Based diet will improve blood glucose (HbA1c), weight (BMI), cholesterol, and blood pressure which are the major risk factors for coronary artery disease. The limitation of this pilot stu- dy is due to its small sample size but has provided very meaningful and encouraging results. A study of larger cohort is in progress for future publication. It illustrates that Plant-Based diet will have a profound health benefits in reducing major coronary risk factors.

\section{Funding}

Not applicable. 

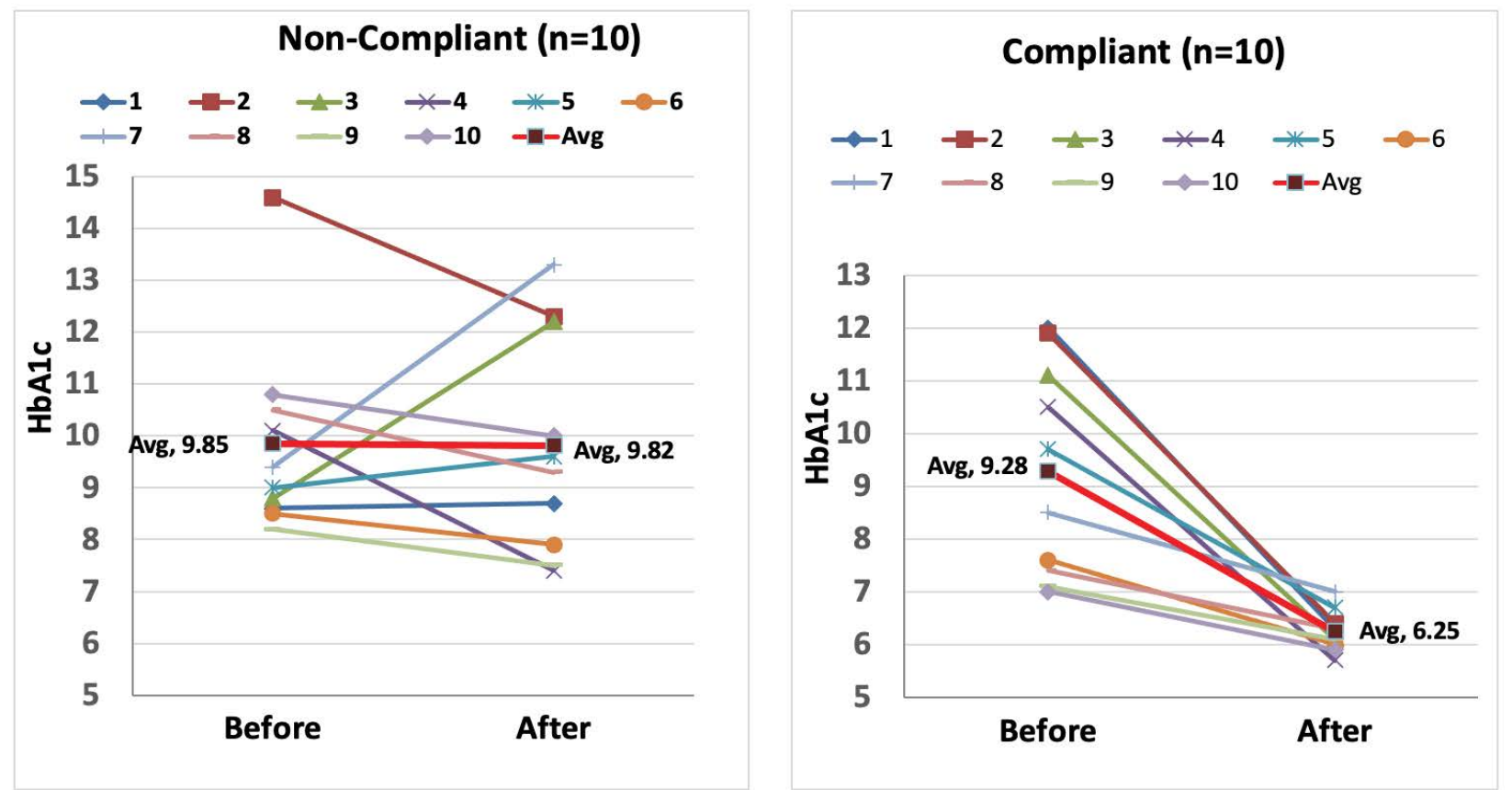

Figure 2: Impact of Plant-Based diet on HbA1c - Non-Compliant Group ( $n=10)$ and Compliant Group $(n=10)$. Non-Compliant Group = without dietary change

Compliant Group = with dietary change

Table 6: Dietary impact on anti-diabetic medications (number of medications used) between the two groups - Non-Compliant vs. Compliant.

\begin{tabular}{|l|l|l|l|l|}
\hline \multicolumn{2}{|l|}{ Non-Compliant $\mathbf{( n = 1 0 )}$} & \multicolumn{2}{l|}{ Compliant $(\mathbf{n}=\mathbf{1 0})$} \\
\hline Patients & Before & After & Before & After \\
\hline 1 & 3 & 2 & 1 & 1 \\
\hline 2 & 2 & 2 & 1 & 1 \\
\hline 3 & 2 & 2 & 1 & 1 \\
\hline 4 & 1 & 1 & 2 & 0 \\
\hline 5 & 3 & 4 & 1 & 1 \\
\hline 6 & 4 & 3 & 2 \\
\hline 7 & 3 & 5 & 1 \\
\hline 8 & 4 & 3 & 4 & 2 \\
\hline 9 & 2 & 4 & 1 & 1 \\
\hline 10 & 2 & 2 & 2 & 2 \\
\hline Average & 2.6 & 2 & 2.1 & 1.2 \\
\hline
\end{tabular}




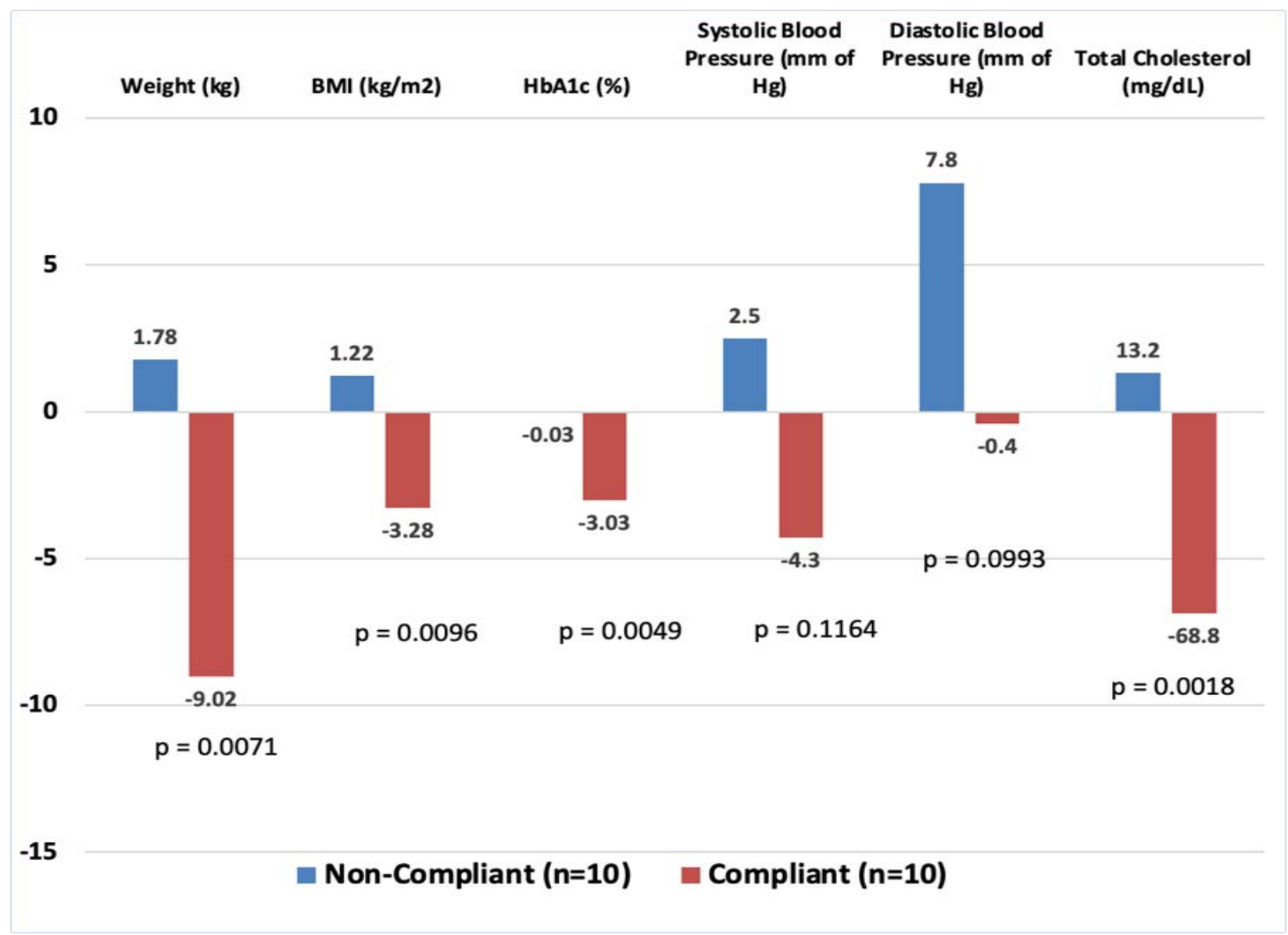

Figure 3: Dietary impact on CAD risk factors.
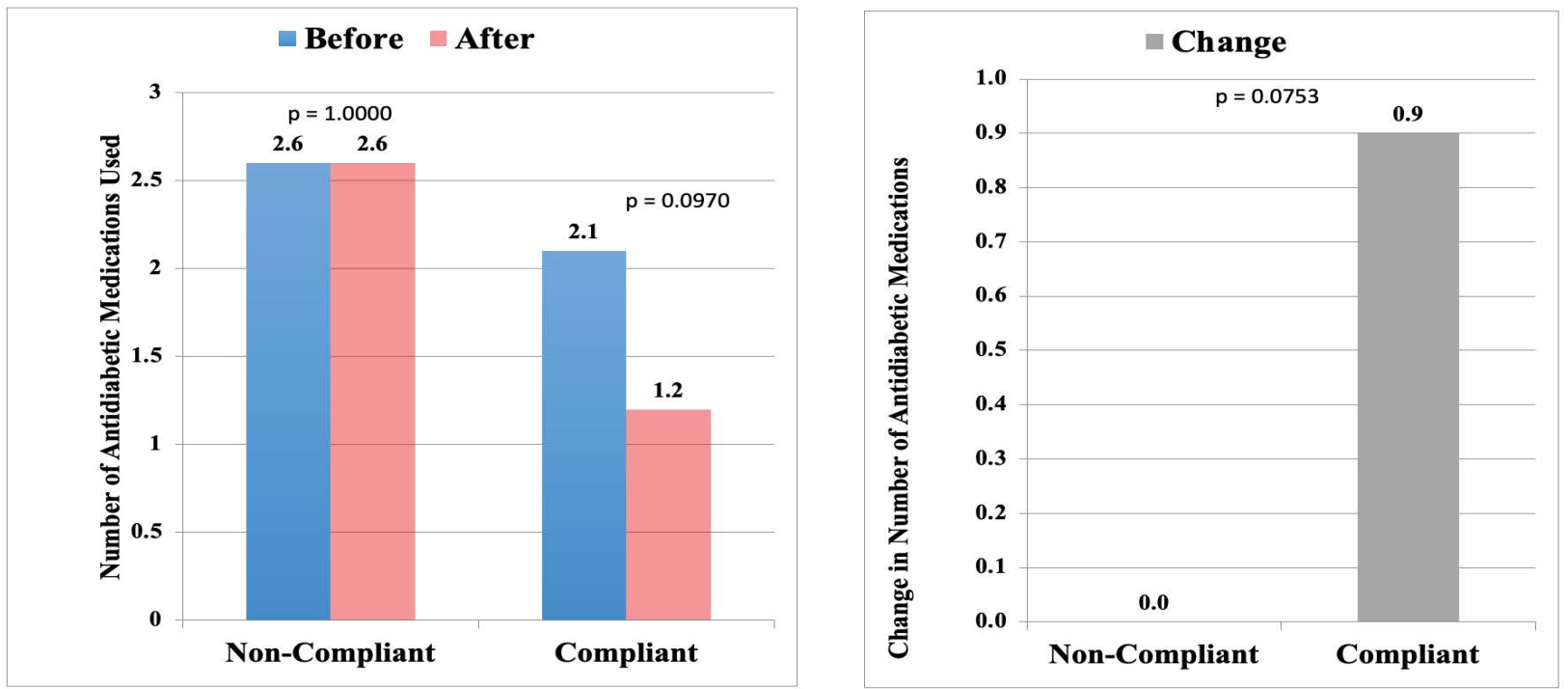

Figure 4: Dietary impact on reduction of anti-diabetic medications and change in the number of medications between the two groups - Non-Compliant $(n=10)$ vs. Compliant $(n=10)$.

\section{Disclosures}

None.

\section{Acknowledgements}

The author acknowledges the contributions of Saghana B. Chakrabortty, MD and Sridhar Panigrahi, M. Sc. for their contribution in making the statistical analysis, tables, and graphs for this paper.

\section{References}

1. Dalen JE, Alpert JS, Goldberg RJ, Weinstein RS (2014) The epidemic of 20(th) century: Coronary heart disease. Am J Med 127: 807-812.

2. Ritchey MD, Wall HK, George MG, Wright JS (2020) US trends in premature heart disease mortality over the past 50 years: Where do we go from here? Trends Cardiovasc Med 30: 364-374. 
3. Cordain L, Eaton SB, Sebastian A, Mann N, Lindeberg S, et al. (2005) Origins and evolution of the Western diet: Health implications for the 21stcentury. Am J Clin Nutr 81: 341354.

4. Sinnett PF, Whyte HM (1973) Epidemiological studies in a total highland population, Tukisenta, New Guinea: Cardiovascular disease and relevant clinical, electrocardiographic, radiological and biochemical findings. J Chronic Dis 26: 265-290.

5. Campbell TC, Parpia B, Chen J (1998) Diet, lifestyle, and the etiology of coronary artery disease: The Cornell China Study. Am J Cardiol 82: 18T-21T.

6. Dawber TR, Moore FE, Mann GV (1957) Coronary heart disease in the Framingham study. Am J Public Health Nations Health 47: 4-24.

7. Kannel WB, McGee DL (1979) Diabetes and cardiovascular disease. The Framingham study. JAMA 241: 2035-2038.

8. Anderson KM, Wilson PW, Odell PM, Kennel WB (1991) An updated coronary risk profile. A statement for health professions. Circulation 83: 356-362.

9. Stamler J, Neaton JD, Cohen JD, Cutler J, Eberly L, et al. (2012) Multiple risk factor intervention trial revisited: A new perspective based on nonfatal and fatal composite endpoints, coronary and cardiovascular, during the trial. J Am Heart Assoc 1: e003640.

10. Ford ES, Ajani UA, Croft JB, Critchley JA, Labarthe DR, et al. (2007) Explaining the decrease in U.S. deaths from coronary disease, 1980 -2000. N Engl J Med 356: 2388-2398.

11. Sidney S, Quesenberry CP, Jaffe MG, Sorel M, NguyenHuynh MN, et al. (2016) Recent trends in cardiovascular mortality in the United States and public health goals. JAMA Cardiol 1: 594-599.

12. Lloyd-Jones DM, Hong Y, Labarthe D, Mozaffarian D, Appel LJ, et al. (2010) Defining and setting national goals for cardiovascular health promotion and disease reduction: The American Heart Association's strategic impact goal through 2020 and beyond. Circulation 121: 586-613.

13. Stampfer MJ, Hu FB, Manson JE, Rimm EB, Willett WC (2000) Primary prevention of coronary heart disease in women through diet and lifestyle. N Engl J Med 343: 16-22.

14. Morrison LM (1960) Diet in coronary atherosclerosis. J Am Med Assoc 173: 884-888.

15. Blankenhorn DH, Hodis HN (1993) Atherosclerosis -- reversal with therapy. West J Med 159: 172-179.

16. Ornish D, Scherwitz LW, Billings JH, Brown SE, Gould KL, et al. (1998) Intensive lifestyle changes for reversal of coronary heart disease. JAMA 280: 2001-2007.

17. Esselstyn Jr CB (2001) Resolving the coronary artery disease epidemic through plant-based nutrition. Prev Cardiol 4: 171-177.

18. Dehghan M, Monte A, Teo KK, Gao Peggy, Sleight P, et al. (2012) Relationship between healthy diet and risk of cardiovascular disease among patients on drug therapies for secondary prevention: A prospective cohort study of 31 546 high-risk individuals from 40 countries. Circulation 126 : 2705-2712.

19. Jousilahti P, Laatikainen T, Peltonen M, Borodulin K, Mannisto S, et al. (2016) Primary prevention and risk factor reduction in coronary heart disease mortality among working aged men and women in eastern Finland over 40 years: Population based observational study. BMJ 352: i721.
20. Wilkins JT, Ning H, Berry J, Zhao L, Dyer AR, et al. (2012) Lifetime risk and years lived free of total cardiovascular disease. JAMA 308: 1795-1801.

21. Berry JD, Dyer A, Cai X, Garside DB, Ning H, et al. (2012) Lifetime risks of cardiovascular disease. N Engl J Med 366: 321-329.

22. Fang J, Yang Q, Hong Y, Loustalot $F$ (2012) Status of cardiovascular health among adult Americans in the 50 states and the District of Columbia, 2009. J Am Heart Assoc 1: e005371.

23. Folsom AR, Yatsuya H, Neeleton JA, Lutsey PL, Cushman $\mathrm{M}$, et al. (2011) Community prevalence of ideal cardiovascular health, by the American Heart association definition, and relationship with cardiovascular disease incidence. J Am Coll Cardiol 57: 1690-1696.

24. Yang Q, Cogswell ME, Flanders WD, Hong Y, Zhang Z, et al. (2012) Trends in cardiovascular health metrics and associations with all-cause and CVD mortality among US adults. JAMA 307: 1273-1283.

25. Chomistek AK, Chiuve SE, Eliassen AH, Mukamal KJ, Willett WC, et al. (2015) Healthy lifestyle in the primordial prevention of cardiovascular disease among young women. $J$ Am Coll Cardiol 65: 43-51.

26. Akesson A, Larsson SC, Discacciati A, Wolk A (2014) Low-risk diet and lifestyle habits in the primary prevention of myocardial infarction in Men: A population-based prospective cohort study. J Am Coll Cardiol 64:1299-1306.

27. Strong JP, Malcom GT, McMahan CA, Tracy RE, Newman III WP, et al. (1999) Prevalence and extent of atherosclerosis in adolescents and young adults: Implications for prevention from the pathobiological determinants of atherosclerosis in youth study. JAMA 281: 727-735.

28. Tuzcu EM, Kapadia SR, Tutar E, Ziada KM, Hobbs RE, et al. (2001) High prevalence of coronary atherosclerosis in asymptomatic teenagers and young adults: Evidence from intravascular ultrasound. Circulation 103: 2705-2710.

29. Weintraub WS, Daniels SR, Burke LE, Franklin BA, Goff Jr DC, et al. (2011) Value of primordial and primary prevention for cardiovascular disease: A policy statement from the American Heart Association. Circulation 124: 967-990.

30. Knapper JT, Ghasemzadeh N, Khayata M, Patel SP, Quyyumi AA, et al. (2015) Time to change our focus: Defining, promoting, and impacting cardiovascular population health. J Am Coll Cardiol 66: 960-971.

31. Khera AV, Emdin CA, Drake I, Natarajan P, Bick AG, et al. (2016) Genetic risk, adherence to a healthy lifestyle, and coronary disease. N Eng J Med 375: 2349-2358.

32. Anderson JW, Smith BM, Gustafson NJ (1994) Health benefits and practical aspects of high-fiber diets. Am J Clin Nutr 59: 1242S-1247S.

33. Snowdon DA, Phillips RL, Fraser GE (1984) Meat consumption and fatal ischemic heart disease. Prev Med 13: 490500 .

34. Le LT, Sabate J (2014) Beyond meatless, the health effects of vegan diets: Findings from the adventist cohorts. Nutrients 6: 2131-2147.

35. Tang WHW, Wang Z, Levison BS, Koeth RA, Britt EB, et al. (2013) Intestinal microbial metabolism of phosphatidylcholine and cardiovascular risk. N Engl J Med 368: 1575-1584.

36. Smith SR (2009) A look at the low-carbohydrate diet. N Eng J Med 361: 2286-2288. 
37. Lara-Castro C, Garvey WT (2008) Intracellular lipid accumulation in liver and muscle and the insulin resistance syndrome. Endocrinol Metab Clin North Am 37: 841-856.

38. Shulman GI (2014) Ectopic fat in insulin resistance, dyslipidemia, and cardiometabolic disease. $\mathrm{N}$ Engl J Med 371: 1131-1141.

39. Greco AV, Mingrone G, Giancaterini A, Manco M, Morroni $M$, et al. (2002) Insulin resistance in morbid obesity: Reversal with intramyocellular fat depletion. Diabetes 51: 144151.

40. Lean MEJ, Leslie WS, Barnes AC, Brosnahan N, Thom G, et al. (2019) Durability of a primary care-led weight-management intervention for remission of type 2 diabetes: 2-year results of the DiRECT open-label, cluster-randomised trial. Lancet Diabetes Endocrinol 7: 344-355.

41. Rabinowitch IM (1935) Effects of the high carbohydrate-low calorie diet upon carbohydrate tolerance in diabetes mellitus. Can Med Assoc J 33: 136-144.

42. Sweeney JS (1927) Dietary factors that influence the dextrose tolerance test. A preliminary study. Arch Intern Med 40: 818-830.

43. Anderson JW, Ward K (1979) High-carbohydrate, high-fiber diets for insulin-treated men with diabetes mellitus. Am J Clin Nutr 32: 2312-2321.

44. Lim EL, Hollingsworth KG, Aribisala BS, Chen MJ, Mathers JC, et al. (2011) Reversal of type 2 diabetes: Normalization of beta cell function with decreased pancreas and liver triacylglycerol. Diabetologia 54: 2506-2514.

45. Anderson JW (2003) Whole grains protect against atherosclerotic cardiovascular disease. Proc Nutr Soc 62: 135142.

46. Craig WJ, Mangels AR, American Dietetic Association (2009) Position of the American Dietetic Association: Vegetarian Diets. J Am Diet Assoc 109: 1266-1282.

47. Maas AHEM, Appelman YEA (2010) Gender differences in coronary heart disease. Neth Heart J 18: 598-602.

48. Knowler WC, Barrett-Conner E, Fowler SE, Hamman RF, Lachin JM, et al. (2002) Reduction in the incidence of type 2 diabetes with lifestyle intervention or metformin. $\mathrm{N}$ Engl J Med 346: 393-403.

49. Lichtenstein AH, Appel LJ, Brands M, Carnethon M, Daniels S, et al. (2006) Diet and lifestyle recommendations revision 2006: A scientific statement from the American $\mathrm{He}-$ art Association nutrition committee. Circulation 114: 82-96.

50. Selvin E, Steffes MW, Zhu H, Matsushita K, Wagenknecht L, et al. (2010) Glycated hemoglobin, diabetes, and cardiovascular risk in nondiabetic adults. $\mathrm{N}$ Engl $\mathrm{J}$ Med 362: 800-811.
51. Svensson B, Baggesen LM, Johnsen SP, Pedersen L, Norrelund $\mathrm{H}$, et al. (2017) Early glycemic control and magnitude of $\mathrm{HbA}_{1 \mathrm{c}}$ reduction predict cardiovascular events and mortality: Population-based cohort study of 24,752 metformin initiators. Diabetes Care 40: 800-807.

52. Kahleova H, Levin S, Barnard N (2017) Cardio-metabolic benefits of plant-based diets. Nutrients 9: 848 .

53. Barnard ND, Cohen J, Jenkins DJA, Turner-McGrievy G, Gloede L, et al. (2009) A low-fat vegan diet and a conventional diabetes diet in the treatment of type 2 diabetes: A randomized, controlled, 74-wk clinical trial. Am J Clin Nutr 89: 1588S-1596S.

54. Wright N, Wilson L, Smith M, Duncan B, McHugh P (2017) The BROAD study: A randomized controlled trial using a whole food plant-based diet in the community for obesity, ischaemic heart disease or diabetes. Nutr Diabetes 7: e256.

55. McInnes N, Smith A, Otto R, Vandermey J, Punthakee Z, et al. (2017) Piloting a remission strategy in type 2 diabetes: results of a randomized control trial. J Clin Endocrinol Metab 102: 1596-1605.

56. Paneni F, Luscher TF (2017) Cardiovascular protection in the treatment of type 2 diabetes: A review of clinical trial results across drug classes. Am J Med 130: S18-S29.

57. Nieuwdrop M, van Haeften TW, Gouverneur MCLG, Mooij HL, van Lieshout MHP, et al. (2006) Loss of endothelial glycocalyx during acute hyperglycemia coincides with endothelial dysfunction and coagulation activation in vivo. Diabetes 55: 480-486.

58. Reitsma S, Slaaf DW, Vink $H$, van Zandvoort MAMJ, oude Egbrink MGA (2007) The endothelial glycocalyx: Composition, functions, and visualization. Eur J Physiol 454: 345359.

59. Nakanishi R, Ceponiene I, Osawa K, Luo Y, Kanisawa $M$, et al. (2016) Plaque progression assessed by a novel semi-automated quantitative plaque software on coronary computed tomography angiography between diabetes and non-diabetes patients: A propensity-score matching study. Atherosclerosis 255: 73-79.

60. Kim U, Leipsic JA, Sellers SL, Shao M, Blanke P, et al. (2018) Natural history of diabetic coronary atherosclerosis by quantitative measurement of serial coronary computed tomographic angiography: Results of the PARADIGM study. JACC Cardiovasc Imaging 11: 1461-1471.

61. Rothberg AE, McEwen LN, Kraftson AT, Fowler CE, Herman WH (2014) Very-low energy diet for type 2 diabetes: An underutilized therapy? J Diabetes Complications 28: 506-510. 